\title{
VIOLENCIA EN EL FÚTBOL Y POLÍTICAS PÚBLICAS EN LA ARGENTINA
}

\author{
SOCCER VIOLENCE AND PUBLIC POLICIES IN ARGENTINA
}

José Antonio Garriga Zucal ${ }^{1}$

Resumen

En la Argentina, la violencia en el fútbol es una problemática que suma año tras año muertos y heridos. Dejando al descubierto el malogrado éxito de las políticas públicas que erran sistemáticamente en la intervención del fenómeno. Proponemos, en estas páginas, poner en diálogo los saberes académicos sobre la violencia en el fútbol con las políticas de prevención o, más bien, con sus ausencias y fracasos. Realizaremos este diálogo a través del estudio del concepto de aguante, desnudando los sentidos de las violencias y las lógicas que podrían tener las políticas de prevención.

Palabras claves: violencia, fútbol, políticas públicas.

\section{Abstract}

In Argentina violence related with soccer is a problem that amount year after year dead and wounded. Exposing the unfortunate success of public policies that systematically err intervention phenomenon. We propose in these pages, put into dialogue academic knowledge on soccer violence prevention policies or rather his absences and failures. Will conduct this dialogue through the study of the concept of endurance, baring the senses of violence and logic that may have prevention policies.

Keywords: violence, soccer, public policies.

Fecha de recepción: 7 de octubre de 2014

Fecha de aprobación: 20 de marzo de 2015

Para citar este artículo:

Garriga Zucal, J. (2015). Violencia en el fútbol y políticas públicas en la Argentina. Lúdica Pedagógica, (21), 91-101.

1 Doctor en Antropología Social (Universidad de Buenos Aires), magíster en Antropología Social (Universidad Nacional de San Martín), licenciado en Antropología Social (Universidad de Buenos Aires). Filiación institucional Conicet/UNSAM. Correo electrónico: garrigajose@hotmail.com 
Desde 1999 estudio la violencia en el fútbol con el objeto de comprender los sentidos -escamoteados- en las acciones violentas. En dos oportunidades realicé exhaustivos trabajos de campo con hinchadas -entre simpatizantes del club Colegiales y del club Huracánanalizando las prácticas violentas, sus significados y la trama relacional que se genera en torno a ellas². En dos oportunidades participé de espacios de gestión en organismos del Estado -provincial y nacional- se genera que buscaban aplacar una problemática que no paraba ni para de crecer. Sendos fracasos coronaron dicha experiencia. Sin embargo, de manera obstinada intenté trazar puentes que permitieran colaborar en la gestión de esa problemática. Este trabajo se suma a estos intentos.

La violencia en el fútbol ha sido profusamente examinada por las investigaciones académicas argentinas en los últimos quince años, con múltiples miradas sociológicas, antropológicas, comunicológicas, etc.-. Un campo fecundo. En este trabajo se propone colaborar con su crecimiento y aportar a la relación entre el saber académico y su practicidad para pensar políticas públicas. Con este objeto se dividió el trabajo en tres partes: en la primera se analizan algunas particularidades del concepto de violencia, y se ejemplifica con lo que acontece en el mundo del fútbol; luego se exhibe la complejidad de una de las dimensiones de la violencia en el fútbol a través del estudio de la noción nativa de aguante, y por último, se señalan los desatinos de la gestión de la seguridad en el fútbol cuando se sustentan en errores conceptuales.

Se empieza por el concepto de violencia y lo que este ilumina para pensar el fenómeno violento en el fútbol. Desde una mirada socioantropológica, dicha noción se presenta como polisémica. La definición de qué es violento y qué no, establece un campo de disputas entre actores diversos posicionados diferencialmente en dispositivos dinámicos de poder (Isla y Míguez, 2003). Definiciones que funcionan como formas de control, ya que en esta sociedad ningún actor social acepta ser definido como violento, dada la ilegitimidad de ese rótulo.

2 En este trabajo se usará este término para hacer referencia a los grupos organizados de espectadores caracterizados por el uso de la violencia, grupos comúnmente llamados barras bravas. Como sinónimos de hinchadas, se usarán los términos barras o bandas.
Entonces, la clasificación de sujetos y acciones como violentos desnuda un campo de lucha por la significación y por la imputación de un estigma (Garriga y Noel, 2010). Por estas razones, el primer paso es desterrar de todo análisis un recurrente error que sustenta algunos enfoques sobre la violencia en el fútbol. Ante cada hecho de violencia, muchos medios de comunicación $\mathrm{y}$ algunos funcionarios públicos ponen en escena un juego de luces y sombras que ilumina las prácticas violentas de unos pocos, culpándolos de las desgracias y desventuras que azotan los estadios, opacando -olvidando con más perversión que ingenuidad- las acciones de otros actores sociales. El resultado de esta operación es atribuir a las llamadas hinchadas todos los males del mundo del fútbol, invisibilizando otras formas de violencia. Los miembros de las hinchadas son uno de los tantos practicantes de acciones violentas en el mundo del fútbol. Los policías, los espectadores que no son parte de los grupos organizados, los periodistas y los jugadores tienen, en diferentes dimensiones, prácticas violentas. Las hinchadas, como sostiene Alabarces (2004), son los únicos de estos actores que hacen de la violencia una marca positiva, ya que reafirman su identidad en la pelea, en la lucha, pero no son los únicos que tienen prácticas posibles de definir como violentas.

Esta reducción del fenómeno tiene muchas implicaciones. Por un lado, invisibiliza las acciones de otros sujetos sociales, reduce el fenómeno violento y escamotea su complejidad. La violencia en el fútbol no es, ante esos ojos, un enmarañado de actores y prácticas sino la sinrazón de unos pocos desequilibrados que "quieren arruinar la fiesta de todos", como repetidas veces leemos o escuchamos en distintos medios. Por otro lado, el foco sobre las hinchadas construye un otro violento y anómalo, ante una multitud de espectadores correctamente adaptados. Gil (2007) señala que existe un consenso general que presenta a los violentos -bandascomo unos pocos individuos que son identificados y repudiados por todos. Estos son los que hay que erradicar para que el fútbol sea la fiesta -pacífica y armónica- que era cuando se inició. Esta imagen simplificada del fenómeno.

Entonces, se vuelve imprescindible cuando hablamos de violencia en el fútbol no reducir el fenómeno a las prácticas de unos pocos. Por ello, proponemos incorporar el plural a la noción de la violencia (Isla y Míguez, 2003), para que desde ahora se piense la(s) violencia(s) 
en el fútbol, comprendiendo la diversidad de actores y representaciones. Este ejercicio devolverá al fenómeno violento su anchura, y desterrará viejas y solidificadas ideas: los violentos son unos pocos y siempre los mismos. Trabajar sobre las violencias en el fútbol permitirá comprender una enmarañada matriz de actores y prácticas que quedan ocultas en las posiciones simplistas que iluminan, siempre a los mismos, como responsables de un todo que los supera ampliamente. Lejos está de este interés negar el rol central que tienen las hinchadas en el fenómeno violento; se busca, por el contrario, una comprensión más acabada que facilite un abordaje profundo de un tema complejo.

Aquí, la segunda meta es analizar la legitimidad de actos y representaciones para ver qué se define como violencia. En esta sociedad existen distintas apreciaciones sobre una misma acción y es necesario mostrarlas e indagar cómo unas se consolidan más legítimas que otras. Riches (1988) sostiene que lo que se define como violencia es el resultado de una disputa por la significación. Esta disputa vincula a actores que desde distintas ópticas pugnan por imponer sentidos y significados. Aquí es necesario pensar las tensiones entre distintas legitimidades, entendiendo que muchas veces lo legítimo para una mayoría no lo es para todos ${ }^{3}$. Una pelea entre hinchadas será definida como violenta por los testigos, pero para los contrincantes esa no será una acción violenta. Esta postura es fundamental para entender por qué luego de una pelea entre hinchadas se presentan denuncias judiciales: las partes enfrentadas saben de antemano cuáles son los posibles desenlaces de un enfrentamiento, acuerdan entonces sobre la legitimidad de sus acciones ${ }^{4}$. Además, los roles dife-

3 Se introduce la peligrosidad de la noción analítica de violencia ya que está contaminada por los valores del sentido común, del lenguaje cotidiano. Valores que peligrosamente pueden definir como violenta toda acción de una alteridad. Por ello se torna necesario ser sistemáticamente rigurosos y medidos cuando se usa el término violencia. Utilización necesaria y posible ya que es un concepto sociológicamente útil a pesar de sus problemas.

4 En octubre de 2005 un juicio, profusamente cubierto por la prensa -no solo deportiva-, juzgó a miembros de la hinchada de Boca por golpear a pares de Chacarita Juniors; el juicio terminó con la negativa de los golpeados a testificar en contra de los victimarios. La prensa hablaba de pacto mafioso, de los códigos secretos de los violentos. Y esta vez estaba cerca de la dimensión del fenómeno. Un informante de Huracán decía que era correcta la actitud de los simpatizantes de Chacarita de no testimoniar contra los de Boca, ya que ambos grupos eran de la barra y si lo hacían estaban rompiendo los códigos. En sintonía con esto, los integrantes de la hinchada de River, acérrimos contrincantes rentes en las interacciones son sumamente relevantes a la hora de definir las acciones. Es así que la misma acción puede ser definida como violencia por un actor cuando es testigo, pero no cuando es ejecutor. Los ejecutores de prácticas definidas por terceros como violentas rara veces definen a sus acciones de esta forma ya que para ellos es legítima.

Entre algunos espectadores del fútbol que no son parte de las hinchadas acontecen muchas veces estas situaciones paradójicas: a la vez que afirman un rotundo no a la violencia recuerdan con agrado su participación en disturbios varios o festejan el robo de banderas a un rival. Un doble discurso resultado de los múltiples mundos sociales en los que estos se ubican. Por un lado, participan de un discurso social que negativiza la violencia y, por otro lado, comparten en la tribuna un espacio donde la violencia posee un valor positivo. Estos espectadores no son esquizofrénicos, ni mucho menos, tienen definiciones contextuales sobre la violencia. Lo mismo acontece con los dirigentes, que ante los medios de prensa se encuentran ligados a las concepciones condenatorias de la violencia en el fútbol pero en otros contextos muestran otras perspectivas sobre los mismos hechos.

Siguiendo esta línea se debe mencionar que no todos los actores sociales están en igualdad de condiciones para imponer su visión del mundo y de la violencia. Si entendemos a la violencia como un campo de disputas por la significación de las prácticas hay que mencionar que en dicho escenario los actores se encuentran en situaciones de poder diferentes, pues no todos los significados tienen las mismas capacidades para volverse legítimos. Es necesario dar cuenta de quiénes, cómo y cuándo definen a ciertas prácticas como violentas. Existen instituciones y agentes sociales -las élites, los medios de comunicación, el Estado- que tienen más poder para definir qué es violencia y qué no. Es necesario recordar aquello que sostiene Isla y Míguez (2003) respecto al rol del Estado en las diversas formas de violencias que azotan nuestra sociedad. Las fuerzas de seguridad son productores o partícipes de numerosos hechos de violencia que deberían prevenir o controlar. No es un dato menor en la comprensión del fenómeno violento en el fútbol argentino que

de Boca, desplegaron una bandera que decía: "Las barras no denuncian". 
un altísimo porcentaje de los más de 270 muertos que tiene en su historia trágica el fútbol argentino son el resultado del accionar policial. Ya se tratará este punto en el apartado final.

Se observa que aquello definido como violencia es el resultado de una matriz de relaciones sociales contextualmente determinadas. Los debates por los sentidos de la acción desnudan el carácter local/contextual de toda definición. Indican, también, que los sentidos de las prácticas violentas no pueden ser comprendidos de forma estática, sino como un fenómeno elaborado históricamente por cada grupo social.

Ahora bien, estas posiciones diferentes se articulan en el mundo del fútbol construyendo un espacio, siempre inestable y cambiante, donde la violencia tiene gran legitimidad. En el fútbol argentino la violencia, en sus diferentes formas, goza de una legitimidad extendida mucho más allá de los límites de la hinchada. El fútbol se ha convertido en un espacio donde actores que rechazan las violencias en otros contextos aquí las acepten, donde la muerte de un espectador rival sea un horizonte posible y, a veces, deseable. Legitimidad, compartida por muchos de los múltiples agentes que pululan por el mundo futbolístico, y que queda oculta por el juego de luces y sombras que visibiliza las acciones violentas de unos y oculta tantas otras formas de violencia.

Es hora de abordar la noción de aguante. Ya se ha mencionado la polisemia del concepto de violencia, y la misma caracterización le cabe a la noción nativa de aguante, que tiene diferentes concepciones según actores y contextos. Puede en algunos casos estar vinculado al fervoroso aliento en las tribunas o, en otros, a la agresión física a un simpatizante rival. Cabe aquí, una vez más, repetir aquello que se sabe sobre este término para mostrar cómo funcionan las lógicas violentas entre las hinchadas de fútbol y explicar las formas sutiles y opacas en que el resto de los actores de este universo acaban legitimando las acciones que dicen rechazar.

Las hinchadas son grupos jerárquicamente organizados que definen la pertenencia grupal por medio de la participación en hechos de violencia. El límite que determina la pertenencia grupal se cruza en la participación en hechos de violencia; para ser parte hay que pelear. Estos hechos nunca son entendidos como violentos desde la perspectiva de los actuantes, sino como prácticas -recurrentemente llamadas combates ${ }^{5}$ que se ajustan a los valores grupales. Poseer aguante es la clave que regula la membrecía.

Sin embargo, en el mundo del fútbol se hallarán distintas definiciones de aguante. Pero la que hacen los miembros de las hinchadas nada tiene que ver con la de otros grupos, que se centra en el estoicismo del espectador ante los reveses deportivos. Aguantar no pasa por alentar todo el partido ni por concurrir a los juegos de su equipo sin importarles nada. Estos valores, que sin duda también son relevantes, no se definen como aguante. Para ellos, tiene que ver con piñas, patadas y pedradas, con soportar los gases lacrimógenos y otros efectos de la represión policial, con cuerpos luchando y resistiendo el dolor. Pelear, afrontar con valentía y coraje una lucha corporal, es prueba de la posesión del aguante. Por esto, para hacer referencia a las prácticas distintivas de las hinchadas usará la expresión aguante violento para diferenciarlo del aguante no violento ${ }^{6}$.

La participación en enfrentamientos transforma al aguante para los hinchadas en un bien simbólico, una manifestación del honor grupal e individual que se constituye en un esquema de clasificación, que define un conjunto de prácticas legítimas. Se distingue y confiere un valor relevante a aquellos que demuestran la posesión del aguante, aquellos que luchan y pelean ya sea contra rivales, policías o entre ellos mismos. Así, se configura un complejo simbólico que establece un conjunto de prácticas capacitadas para definir un modelo ideal que diferencia poseedores y desposeídos.

Las hinchadas definen positivamente la posesión del aguante, fuera de esos límites hay una percepción ambigua, a veces negativa, de esas prácticas que son consideradas violentas. El honor adquirido en un combate establece el límite de los que participan o no de esta comunidad. La lucha física como límite establece variados mecanismos para construir la frontera de la comunidad aguantadora (Moreira, 2005).

La masculinidad y el cuerpo son eficaces espacios simbólicos y prácticos donde se edifican las diferencias. El macho como ejemplo de una masculinidad

\footnotetext{
5 Los términos nativos aparecerán en itálica para diferenciar las voces de nuestros interlocutores de las analíticas.

6 Para ampliar esta diferencia, ver Alabarces, Garriga y Moreira (2008).
} 
aguantadora ordena un conjunto de similitudes y diferencias. Los que se paran, los que no corren y tienen huevos son parte de la comunidad que deja más allá de sus fronteras a los cobardes, definidos como cagones (Archetti, 1985). Por su parte, el cuerpo contribuye a la lógica aguantadora en una doble operación. Por un lado, el aguante crea representaciones ideales de un modelo de cuerpo asociado, por lo general, a un cuerpo grande, con cicatrices, resistente al dolor y a los abusos de las drogas o bebidas alcohólicas. Por otro lado, a través de acciones físicas funda la distinción que en otro plano solo parecía un conjunto de imágenes corporales. El cuerpo pelea y es en esa acción que se define como cuerpo aguantador (Alabarces y Garriga, 2007).

Cada grupo define un conjunto de valores que delimitan la pertenencia y el aguante es la clave de membrecía al mundo de las barras. Los integrantes de las hinchadas, cuando recuerdan su iniciación, su ingreso al mundo de pares, relatan sus primeros enfrentamientos físicos. El aguante es una forma especial de identificación que organiza sentidos de pertenencia, una contraseña que indica un nosotros, que estampa la membrecía a un grupo. Las prácticas violentas definidas desde la mirada convencional como ejemplo de ruptura social, como el páramo de la sociabilidad, como el desierto de la identidad se torna un espacio habitable: el aguante es un espacio identitario.

Además, el aguante es una identidad inminentemente práctica. Son las acciones y no los discursos los que establecen la membrecía. Los que dicen aguantársela deben probarlo en luchas corporales. Los miembros de las hinchadas cantan canciones, recuerdan enfrentamientos, muestran cicatrices como testimonio de viejas peleas pero nada de esto exhibe, al fin y al cabo, el aguante; bien simbólico que solo puede probarse en un duelo físico. La identidad aguantadora es, por tanto, sumamente inestable y debe siempre ser probada. No basta con sostener el aguante en el discurso, hay que pelearse.

Cabe mencionar que las hinchadas en el fútbol argentino son grupalidades socialmente heterogéneas, es un error recurrente reducir la pertenencia social a los sectores pobres o marginales. Comunidad compleja donde conviven sujetos de los sectores populares con otros de las clases medias, que comparten un conjunto de valores que los distinguen y los diferencian. La diversidad se homogeniza bajo la lógica del aguante.
Ser miembro de la barra incluye a los actores en un grupo de pares, jerárquico y conflictivamente complejo, que establece vínculos de camaradería, protección y apoyo mutuo. Irrumpen en el interior del grupo las interacciones agresivas mixturadas con nociones de solidaridad y compañerismo, una trama de vínculos de ayudas, apoyos y lealtades. En caso de ser detenidos o lesionados emergen entre los participantes de las hinchadas redes de protección que se encargan de auxiliar a los compañeros caídos, según su punto de vista, en desgracia.

Pero no solo entre pares circulan bienes y favores, sino que también el aguante es una moneda de interacción que los vincula y relaciona con actores sociales, múltiples y variados, que están por fuera de los límites de esta comunidad. En distintas dimensiones, y según diversas estrategias, la hinchada se vuelve un actor social relevante con el cual los distintos actores del mundo futbolístico se vinculan. Por esto, tienen vínculos con jugadores, directores técnicos, policías, dirigentes políticos, etc. Es así que la particularidad que los caracteriza, el aguante-violento, muchas veces estigmatizado, no solo no los excluye del mundo social sino que, por el contrario, los incluye en una red de interacciones sociales. La membrecía instaura relaciones sociales y arma el andamiaje de vínculos diversos. Cabe, como ejemplo, iluminar las relaciones que los miembros de las hinchadas poseen con los dirigentes de las instituciones deportivas. Entre participantes de la hinchada y dirigentes existe una relación de interdependencia; ambas partes precisan de bienes y servicios que el otro puede ofrecerles. Se establece por ello una relación de intercambio. Estas relaciones no son armónicas ni mucho menos. Los vínculos son conflictivos y complejos, pero estables por cuanto las partes se necesiten. Vínculos que se establecen y sostienen en la identidad aguantadora. Así se vinculan actores sociales con definiciones muy distintas sobre la violencia. La conducta violenta convertida en señal de pertenencia es, entonces, un nexo con otros actores sociales -ubicados en lugares diversos y distantes del mapa social-.

Para retomar, los participantes de la hinchada acceden a variados recursos materiales como beneficios de esta membrecía: viajes, dinero, ropa deportiva de la institución, trabajos diversos, etc. Sin embargo, es imposible reducir los deseos de pertenencia a las cuestiones materiales. Los intereses que llevan a los actores a la 
participación en estos grupos son múltiples. El acceso a recursos es uno de los argumentos que inclinan la participación mas no es el único. Otros aspectos en común, no materiales, ordenan los sentidos de la inserción en esta comunidad. En un trabajo escrito junto a Cabrera (Cabrera y Garriga, 2014), polemizando con los investigadores que sostienen que las barrabravas se organizan a partir de la búsqueda de recursos (Sain y Rodríguez, 2014 y D’Angelo, 2011), se afirmó que lo que organiza la pertenencia a las barras es el aguante-violencia. De nuevo, es conveniente señalar que los recursos buscados y encontrados por las barras bravas no son la particularidad que los define. Dos razones sostienen esta afirmación: a) los jóvenes que ingresan a una barra poco saben de los negocios del grupo y no tienen, en la mayoría de los casos, en el horizonte conseguir recursos por medio de esta pertenencia; desean ser parte, ser como, pero más por el prestigio que por el dinero, y b) sería un error asumir que el escenario que se piensa para las barras de los clubes denominados grandes, donde los recursos abundan, es generalizable a todas los otros clubes. Si la disputa por los recursos es lo que explica la violencia, cómo explicarla donde los recursos son tan mínimos que a veces no existen. La clave está en dar cuenta que la búsqueda de prestigio y respeto motiva, entre otras cosas, la inclusión de muchos jóvenes que ansían reconocimiento societal, aún a costa de que ese reconocimiento sea comúnmente conceptualizado como negativo. La reputación de la violencia funge como atractivo. Además, la avidez de pertenencia, en un escenario social donde las identidades están en franca decadencia, se torna, también, un importante incentivo. 0 sea, ser alguien o ser parte en un determinado entramado de relaciones sociales es un motivo que moviliza la participación en estas comunidades. Un aura, que mixtura grados de fascinación con piscas de aversión, unge a los aguantadores. Atracción que legitima a los espectadores a querer ser definidos como aguantadores y pasar a engrosar las filas de la hinchada; fascinación que legitima al aguante-violento.

Se mencionaba que los sentidos que originan la participación son múltiples, que conjugan intereses materiales con morales. Ahora, es ineludible afirmar que dada la diversidad de actores que ingresan a estos mundos los intereses son diferentes. Las partes articulan una mismidad basada en el aguante, inestable, de fronteras porosas, pero no deja de ser un articulado de actores diversos con múltiples intereses. Las estrategias que guían la participación es diferencial según los actores, diferentes razones motivan la participación según criterios de clase y edad. Además, la participación en las hinchadas es para muchos de sus miembros una membrecía de larga duración y, por ello, es obvio que los intereses que motivaron su participación en la adolescencia sean muy distintos a los que la guían en la vida adulta.

Los miembros de la comunidad aguantadora hacen de la violencia un recurso de distinción, una señal de pertenencia grupal que los diferencia y distingue. Esto es posible solo a través de los mecanismos de exhibición y muestra del aguante. Las estrategias de distinción son contextuales y relacionales, ya que, según los contextos y las relaciones, se utilizan distintos mecanismos de diferenciación. En algunos casos es necesario el uso de la violencia física y, en otros, simplemente es preciso cantar una canción o relatar una pelea.

La violencia no es una particularidad natural del sujeto sino un recurso. Estos sujetos que en unas relaciones hacen de la violencia su señal de pertenecía, su marca distintiva, en otras relaciones manipulan otros recursos, otras señales. Estratégicamente se usa o no la violencia según las interacciones. En una entrevista, un hincha revelaba que en algunas interacciones se ponía el disfraz de barra. Cuando la situación lo ameritaba, él sacaba a relucir gestos, modismos, frases que lo ubicaban dentro de la comunidad aguantadora. Contaba en tono jocoso cómo de esa forma conseguía ropa de los jugadores o algún favor de los dirigentes. La identidad es contextual y tiene que ver con el tipo de relaciones que establecen las personas. En cada contexto, explota y juega con su pertenencia. Los miembros de la hinchada, además de ser aguantadores, son padres, maridos, trabajadores, ladrones, etc. En cada una de esas dimensiones de la vida serán otros los recursos que guíen sus interacciones. Otro hincha contaba, a manera de contraejemplo de lo expuesto, que cuando iba a buscar a su hijo al jardín se ponía el disfraz de padre. Esto es un ejemplo de la multiplicidad de identidades y recursos asociados a ellas. Un sujeto que en un determinado momento y ante una situación determinada saca a relucir su pertenencia grupal y que en otros contextos puede o debe ocultarla. Se destierran precisamente las concepciones que ven violentos $a$ 
troche y moche como muestra de una esencia, de una ontología, para observar la complejidad de un escenario social que habilita en algunos vínculos la violencia como moneda de relación social.

Los miembros de las hinchadas se incluyen en múltiples relaciones sociales donde la violencia como interacción positiva está vedada; en estas, otros papeles se ponen en escena y los actores sociales representan otros roles. Vale recordar, por su claridad, el caso de un miembro de la hinchada que los sábados hacía de la violencia en los estadios su carta de presentación formal, y los domingos era parte de una agrupación católica como los boy scouts.

Se afirma, entonces, que la violencia es el valor predominante de un tipo de relación social. Los sujetos establecen otras relaciones sociales no signadas por este recurso distintivo. Pero, sin duda, las formas de la violencia se interiorizan de maneras diversas. La violencia se sedimenta según los sujetos, según las trayectorias y el entramado de vínculo sociales en los que están insertos los integrantes de la hinchada. Estas diferencias hacen que algunos sugieran que en ciertas ocasiones se ponen el disfraz de barras y otros, por el contrario, dicen ponerse el disfraz de padres. Esto es el resultado de los tipos de vínculos que forman a los sujetos.

Por último es necesario mencionar que comúnmente en la Argentina, algunos comunicadores y los encargados de la planificación de políticas públicas, imputan la violencia como un rasgo distintivo de los más pobres. Ya se mencionaba que es imposible pensar que las prácticas violentas son una particularidad solo de las hinchadas; ahora ha que afirmar que las acciones violentas no son una característica de los más pobres. Nuevamente un efecto de luces y sombras ilumina las prácticas de los sujetos más vulnerados, olvidando y dejando a resguardo las acciones de los más poderosos, quienes poseen el dominio de definir qué es violencia y qué no. Otra vez, la operación que realiza esa ligazón -que se propone desterrar- tiene como objeto imputar la violencia como una particularidad siempre característica de una minoría lejana y nunca como una característica que atraviesa todo el tejido social. Es de conocimiento que en la Argentina se arrojan piedras desde costosas plateas, que adinerados dirigentes de clubes amenazan con armas de fuego a simpatizantes rivales y que la composición social de las hinchadas es sumamente heterogénea. Por ello, es un error mayúsculo creer que solo los más pobres son violentos. En el mundo del fútbol no todos los pobres protagonizan acciones violentas ni todos los que protagonizan acciones violentas son pobres.

Para finalizar, es prudente resaltar los equívocos sobre los que se sustentan las políticas públicas que gestionan -desean- la violencia en los estadios. Se recurre a la expresión "desean", pues lo que caracteriza la intervención en estos asuntos es la ausencia. El Estado, en sus diferentes órdenes -nacional, provincial o municipal- debería tener un rol central en la prevención de la violencia, pero poco hace. 0 carga las tintas sobre su poder de policía y cumple un rol represivo, o en el mejor de los casos, centra la prevención en la creación de leyes que penalicen las formas de violencia; tales políticas son, a la luz de sus resultados, sumamente inútiles. Estos fracasos se analizan en tres ejes:

1. Luego de haber transitado el apartado anterior, sobrados argumentos tendrán los lectores para comprender los sentidos sociales de la violencia, significados que impiden sitiar a estas prácticas más allá de la razón. Las acciones violentas no son ejemplo de la sinrazón. Y más aún, estos sentidos son el resultado de múltiples causas imbricadas, que articulan, por ejemplo, de forma compleja razones materiales con dimensiones del honor y la identidad de género. Sin embargo, la violencia en el fútbol es interpretada muchas veces por los encargados de pensar políticas públicas de prevención como ejemplo máximo de sinrazón e incivilización. Las dos concepciones se entrecruzan, la razón define al actor social de la sociedad civilizada. Civilización y razón son parte de un mismo argumento, cuyo resultado es ubicar a la sinrazón como particularidad que distingue al imperio de lo incivilizado. Este silogismo enlaza dos representaciones sobre los protagonistas de hechos violentos en el fútbol. Por un lado, son personificados como irracionales, bestias y locos; animalizados o interpretados como sujetos patológicos, son desplazados más allá de los límites de la razón. Por otro lado, y en continuidad con la primera interpretación, son concebidos como bárbaros o 
salvajes, alejados de la civilización. Los actores de hechos violentos aparecen como el testimonio de un pasado que se creía superado. La violencia aparece como producto de una alteridad radical, distante del nosotros racional y civilizado, anomalía disruptiva del orden social que debe ser eliminada. La falta de razón es anómala y, por ende, también sus representaciones.

Niegan la dimensión identitaria del aguante y ocultan, ya sea por miopía analítica o ideológica, las razones culturales que sustentan las acciones violentas. Razones que deben ser estudiadas y afrontadas para intervenir en el fenómeno que aquí concierne. Las formas de diferenciarse y distinguirse como aguantadores reconocen maneras válidas e inválidas de proceder. Las acciones violentas tienen, desde la visión de los actores, límites significativos que definen qué se puede hacer y qué no en el mundo del aguante. Una lógica que instaura modos correctos o incorrectos de actuar según los acontecimientos. Lejos, muy lejos, quedan aquellas posturas prejuiciosas que observan, en las situaciones de violencia, caos y desorden. La lógica del aguante-violento dista profundamente de nuestras formas de concebir el mundo social pero solo una profunda miopía etnocéntrica puede negar sus sentidos y valores.

Escudriñar sentidos nutre de herramientas para planificar políticas de prevención. Para ser efectivas, las políticas de prevención deberían abordar estos sentidos y modificarlos. Por el contrario, la negación de la significación deja a la gestión de la seguridad la idea de encontrarse ante actores anómalos que les cabe como única medida la represión.

La noción de irracionalidad lleva a concebir la violencia como una particularidad ontológica de los sujetos y obtura toda política de prevención. Prevenir la violencia se transforma así, por ignorancia y perversión, en la política de eliminación de los violentos y no de las causas sociales y culturales que producen las acciones. Es sumamente relevante exhibir el traspié conceptual de los que transforman a los sujetos que consuman acciones violentas en violentos. Esta desacertada idea, sustentada en una concepción de la violencia como impulso irracional, impide toda política de prevención acabada al concebir a la violencia como una particularidad ontológica de sujetos que deben ser erradicados. Los que comenten actos violentos son señalados, demonizados, reprimidos y encarcelados ya que sus acciones son parte de una naturaleza que no pueden cambiar y, por ello, no existe prevención posible, solo represión.

Por otro lado, pero en el mismo sentido, es relevante recalcar que a sabiendas de la lógica del aguante que se presentó en el apartado anterior, la confusión -que diariamente realizan funcionarios, periodistas, futbolistas, etc.- entre los sentidos diferentes del aguante termina legitimando moralmente las acciones violentas. Cuando los periodistas confunden violencia con folklore, cuando los gestores de políticas públicas definen a los miembros de las hinchadas como ejemplo de pasiones, cuando los espectadores viven las prácticas violentas, cuando los dirigentes reciben como embajadores a los barras consienten las violencias que definen al aguante. Estos actores que piensan a la violencia como una particularidad de una alteridad distante, no solo son (somos) practicantes de acciones violentas opacadas sino que, además, todos contribuyen a legitimar las de las barras. Es necesario implementar estrategias de deslegitimación de la violencia, que multipliquen la fiesta del fútbol sin validar las acciones violentas. Estas políticas de deslegitimación deben estar orientadas a todos los actores del fútbol, para que no se reproduzcan valores y significaciones que legitiman la violencia.

Aquí se observa cómo la legitimidad de las acciones se entrecruza con las legalidades. La ley es, sin duda, un poderoso instrumento para nutrir las acciones de legitimidad. Aunque también es cierto que el efecto de la ley no otorga mágicamente ilegitimidad a las acciones que tienen legitimidades. Se puede ver que la eficacia simbólica de la ley es mínima, 
ya que no tiene ningún maná y que la simple aparición de la norma en el boletín oficial no hace que la violencia desaparezca. Solo unos pocos pueden creer que con una ley se solucionan problemas que tienen fundamentos sociales y raíces culturales. Las leyes persiguen la violencia en el fútbol -solo un tipo de violencia- y logran detenciones mas no pueden cambiar los valores legítimos que tiene la violencia entre sus actores. Las formas culturales que sustentan la violencia en el fútbol no pierden su legitimidad por ser ilegales. Para ejemplificar, es pertinente mencionar que los líderes de la barra de River y de Boca estuvieron detenidos, pero no se pudo lograr que una innumerable cantidad de hinchas quieran ocupar el lugar vacante de esos líderes.

Las políticas de prevención en torno a la violencia deberían trabajar en la deconstrucción de los valores que legitiman la violencia en el fútbol. Mostrando en estas lides una gran incapacidad. Y la incapacidad está en su punto de partida, el cual lo constituye una imposibilidad intelectual; los encargados de pensar la violencia no la pueden pensar porque la creen impensable. Piensan que la violencia es la sinrazón, lo ilógico, lo sinsentido y, por ende, no puede ser más que reprimido y nunca prevenido. 0 los piensan -a los miembros de las barras- como mercenarios que buscan réditos materiales en las luchas violentas opacando los sentidos de la violencia y la complejidad del fenómeno, errando el enfoque de la prevención.

2. El Estado, a través de su función como poder de policía, es parte de la violencia en el deporte en dos dimensiones. Por un lado, por ineficacia de los operativos policiales que terminan muchas veces provocando el enfrentamiento entre parcialidades rivales que debería prevenir. Son numerosos los casos de que la escolta policial termina llevando a sus escoltados a situaciones de enfrentamiento. Por otro, la policía es uno de los actores más violentos en el ámbito del fútbol. Una gran cantidad de los muertos y heridos en el fútbol se deben a los abusos de las fuerzas de seguridad.

La participación de la policía en hechos violentos se debe a diferentes factores. Puede ser por ignorancia en el manejo de públicos masivos, ya que las fuerzas de seguridad deberían estar capacitadas en el control de masas, pero no lo están. Esta ignorancia se transforma en temores que surgen en los momentos de caos, lo que conduce a más caos. La falta de capacitación hace que ante las situaciones de peligro los policías actúen violentamente. Pero además, estos muchas veces manejan los mismos códigos que los hinchas $\mathrm{y}$, ante una incitación a la violencia, no se muestran como el brazo armado del Estado que debe ser, cauto y paciente ante los escupitajos, insultos y otros maltratos, sino que reaccionan violentamente. También, algunos policías, no todos, quieren mostrar que se la aguantan y se enfrentan con actores a quienes conciben como rivales en la disputa simbólica de la hombría y el coraje. Un policía una vez dijo: "[...] como los corrimos por la Amancio Alcorta, qué cagones que son". En la frase se hacen visibles las similitudes y continuidades entre los policías y las barras. El entrevistado se refería a un episodio donde la guardia de infantería a la que el pertenecía dispersó con gases lacrimógenos y a bastonazos a la barra de Huracán. Dispersión que, según él, mostraba que la barra no se la aguantaba como decían, ya que si hubiesen tenido aguante no corrían. Vale recordar que correr remite a prácticas violentas, a expulsar por la fuerza. El que corre no tiene aguante y es un cobarde, cagón en términos nativos. El policía utilizaba los mismos términos que los informantes barras, legitimando formas de la violencia policial.

3. El Estado tiene las herramientas para construir la ilegitimidad de la violencia, ya que posee la capacidad de definición, pero en el caso de la violencia en el fútbol cumple un rol complejo y dudoso. Confusión que se ejemplifica en dos caminos diferentes. 
Por un lado, los encargados de la seguridad en sus discursos, en sus proyectos de ley, contribuyen a pensar que el único actor violento en el mundo del fútbol son las barras. Esta diferencia construye una distinción entre violencias tolerables e intolerables. La violencia de las hinchadas es inaceptable por cuanto es concebida como positiva por sus practicantes. Así, parece que lo desatinado de su accionar no son sus prácticas, comparados con otros gestos igualmente violentos, sino el hecho de darle legitimidad y validez. Y en esto, sin duda, las hinchadas son únicas. Son el único de todos los grupos que tienen acciones violentas en el fútbol que no solo le dan valor positivo sino que, además, buscan muchas veces hacer visibles estas características que los distinguen. Esto hace que haya violencias que son más tolerables según los sujetos sociales. La violencia de un espectador que arroja piedras e insulta no es equiparable a la de un miembro de la barra que insulta y arroja piedras. Esto pudo verse en plenitud en los incidentes de mayo de 2005 en el estadio de Boca Juniors. Un espectador situado en las plateas invadió el campo, golpeó a un jugador mexicano y se refugió nuevamente en su sector, auxiliado por sus compañeros plateistas. El ministro del Interior de ese entonces, Aníbal Fernández, sostuvo que cuando la policía intentó intervenir "[fueron] agredidos por una cantidad importante de gente, que no son barrabravas, son socios. Tampoco en este caso uno va a hacer una batalla campal" (Olé, 16 de mayo de 2005). El comentario de la autoridad pública demuestra que hay jerarquías respecto a lo intolerable de la violencia; un límite que se mueve según las circunstancias y situaciones. Si los agresores hubieran sido miembros de la hinchada, el acto hubiera sido intolerable, la represión hubiera sido tolerada y la batalla campal, justificada. El Estado, al perseguir algunas formas de violencia y no otras, se conforma como un partícipe secundario de estas otras. Permite algunas formas de violencia que aunque ilegales no son tan ilegitimas. Estas violencias son moderadamente aceptadas y no reprimidas.

Por otro lado, la política de seguridad más notoria en la última década fue la prohibición de acceso a los estadios del público visitante. Política ineficaz y sumamente problemática en su matriz conceptual. Esta prohibición construye y re-construye la imagen de otredad como peligrosa. El espectador de equipo rival es, de buenas a primeras, interpretado como potencial violento y se crea sobre este una representación del peligro. Se piensan las políticas en torno a la exclusión, ya que el simpatizante rival debe ser eliminado, anulado, suprimido. Así el Estado refuerza indirectamente los significados que en torno al fútbol estipulan la eliminación del rival como forma de exhibir aguante. Para colmo, la política de prohibición de acceso a espectadores visitantes se muestra en extremo ineficaz, ya que la violencia no cesa. Los episodios de violencia no tuvieron un paliativo desde la implementación de esta precipitada e irreflexiva medida. La raíz de este fracaso es que la ausencia del otro no modifica la lógica del aguante y las barras siguen insertas en estas razones, modificando solo sus potenciales contrincantes. Radicalizándose, precisamente, las luchas intestinas entre facciones de las hinchadas para ver quién tiene más aguante o luchando con la policía, pero sin cambiar los valores y sentidos que motivan las disputas. Una vez más, el total desentendimiento de las lógicas violentas. 


\section{REFERENCIAS BIBLIOGRÁFICAS}

Alabarces, P. (2004). Crónica del aguante. Fútbol, violencia y política. Buenos Aires: Capital Intelectual.

Alabarces, P. y Garriga, J. (2007). Identidades corporales: entre el relato y el aguante. Campos. Revista de Antropología Social 8(1), 145-165.

Alabarces, P.; Garriga, J. y Moreira, M. (2008). El aguante y las hinchadas argentinas. Una relación violenta. Horizontes Antropológicos 14 (30). 113-136.

Archetti, E. (1985). Fútbol y ethos. Buenos Aires: Flacso.

Cabrera, N, y Garriga, J. (2014). Aguante y transgresión: organización y lazos sociales en las barras bravas del fútbol argentino. Ponencia presentada en el II Seminario Internacional sobre Historia de la Violencia en América Latina siglo XIX y XX. Córdoba.

D’Angelo. N. (2011). La nueva conflictividad de las barras bravas en Argentina: una lectura a la luz de la teoría de redes. Revista de Investigación Social 8(13) 55-75.

Garriga, J. y Noel, G. (2010). Notas para una definición antropológica de la violencia. Un debate en curso. Publicar 8(IX), 97-121.
Gil, G. (2002). Fútbol e identidades locales. Dilemas de fundación y conflictos latentes en una ciudad "feliz". Buenos Aires: Miño y Dávila Editores.

Isla, A. y Míguez, D. (2003). De la violencia y sus modos. Introducción. En: A. Isla y D. Míguez (ed.). Heridas urbanas. Violencia delictiva y transformaciones sociales en los noventa (pp. 1-32). Buenos Aires: Editorial de las Ciencias.

Moreira, M. (2005). Trofeos de guerra y hombres de honor. En: P. Alabarces (ed.). Hichadas (pp. 75-89). Buenos Aires: Prometeo.

Riches D. (1988). El fenómeno de la violencia. Madrid: Ediciones Pirámide.

Sain, M. y Rodríguez, N. (2014). Los actores y la seguridad en el fútbol. Una lectura desde Argentina. En: F. Carrión Mena y M.J. Rodríguez (coord.). Luchas urbanas alrededor del fútbol (pp. 225-259). Buenos Aires: Café de las Ciudades. 